\title{
Perceptual Demonstrative Thought: A Property-Dependent Theory
}

\author{
Sean Crawford ${ }^{1}$
}

Published online: 5 February 2018

(c) The Author(s) 2018. This article is an open access publication

\begin{abstract}
The paper presents a new theory of perceptual demonstrative thought, the property-dependent theory. It argues that the theory is superior to both the object-dependent theory (Evans, McDowell) and the object-independent theory (Burge).
\end{abstract}

Keywords Perceptual demonstrative thought · Object-dependent thought · Truth-conditional semantics · Tyler Burge · Gareth Evans · John McDowell

\section{Introduction}

Perceptual demonstrative thoughts are thoughts about things to which the thinker stands in some kind of perceptual relation and which are such that the perceptual relation in question makes possible the very thinking of the thought. Such thoughts include a variety of types of psychological attitude: I can judge that the object I am seeing is such-and-such, wonder whether it is such-and-such, want it to be such-andsuch, and so on. The kinds of things such thoughts can be directed at include not only material objects but also the sensible qualities of such objects. We also make perceptual demonstrative reference to things whose ontological status is somewhat less robust than objects and their sensible qualities, such as the sky, rainbows, sunsets, shadows, mirror images, directions, distances, light, sounds, odours, textures, and tastes. But whatever kind of thing we are dealing with, it is on the basis of perceiving it that were are able to have a perceptual demonstrative thought about it. Perceptual demonstrative thoughts are thus events that depend upon continuing episodes of perceptual acquaintance with the objects thought about. Such thoughts take the canonical schematic form That is $F$ or That $F$ is $G$.

Many philosophers maintain that the intentional mental content of the demonstrative thought component That or That $F$ is irreducibly demonstrative. ${ }^{1}$ It is not, in other words, equivalent to the intentional mental content of a concept devoid of demonstrative elements. ${ }^{2}$ Such philosophers

Sean Crawford

sean.crawford@manchester.ac.uk

1 University of Manchester, Manchester M13 9PL, UK reject the view, for example, that the content of a demonstrative thought is entirely demonstrative-free and incorporates only indexical elements referring to the present time and to the subject, which is the case, for instance, in the thoughts The $F$ in front of me now is $G$, or The object I am now looking at is $G$, or The F I am now attending to is $G$-thoughts which are all such that they reach their targets by the latter uniquely fitting the descriptive content of the former, a descriptive content that contains non-demonstrative or "pure" indexical elements. ${ }^{3}$ They also reject the view that the content of a demonstrative thought is equivalent to a content containing demonstrative concepts that do not refer to the object of the thought, but rather, to the subject's perceptual experience of the object (and perhaps also to the spatial location of the object) as is the case with the thought

\footnotetext{
1 Although the distinction between simple or "bare" demonstrative constructions ('that') and complex demonstrative constructions ('that F') in language is philosophically important, and the nature of the latter in particular raises difficult and controversial questions, for example, about the precise semantic contribution of the noun ' $F$ ' to sentences in which it occurs (whether it contributes to truth conditions or helps to determine reference, e.g.), nothing in this essay turns on any of these orthogonal issues. For extensive discussion of these matters, see Larson and Segal (1995) and Lepore and Ludwig (2000).

2 Evans (1982), McDowell (1977, 1984, 1986, 1991), Davies (1981a), Bach (1982, 1987), Burge (1977, 1983, 1991, 2007, 2009), Segal (1989), Noonan (1986, 1991), Peacocke (1981), Recanati (1993), McCulloch (1989).

3 Schiffer (1978) defends such a view, though he later (1978, p. 281n9) appears to retract it. Cf. Blackburn (1984), ch. 9. Austin (1990, ch. 2) provides a thorough and convincing critique of Schiffer's view and indeed any view purporting to reduce demonstrative thought to non-demonstrative thought.
} 
The object (there) causing this visual experience is $G{ }^{4}$ The objection is that when I look out the window and see, say, a raccoon in my backyard, and think to myself That raccoon is wounded, I am not thinking about myself, the current time, my perceptual experience or causation (though of course I could be, especially if am a philosopher or psychologist). However these factors may enter into an account of what it is for me to have such a demonstrative thought, as causally or constitutively necessary enabling conditions, I do not deploy concepts of any of these things in my actual thinking of the thought, in order to form a condition uniquely met by some object. Moreover, even if, on some occasions, I do (or could) make demonstrative reference to my perceptual experiences or features thereof, in order to form some general condition satisfied by some one object, this is an ability that I acquire after the ability to make demonstrative reference to external physical objects, so it must be possible to think demonstratively about such objects without making reference to perceptual experience itself. ${ }^{5}$ And obviously young children (and perhaps even babies and animals) are perfectly capable of having perceptual demonstrative thoughts, but do not possess concepts of perception or causation or themselves that they could even bring to bear in their perceptual thinking. McDowell sums up the general point nicely when he says that 'a perceptual demonstrative thought surely homes in on its object not by containing a general specification, with the object figuring in the thought as what fits the specification, but by virtue of the way this sort of thinking exploits the perceptible presence of the object itself' (1984, p. 105).

Now, some of those who defend this irreducibility take the demonstrative content to be object-dependent-that is, take the object of thought to be involved essentially in the individuation of the content of the thought—and some do not. ${ }^{6}$ Consider the (visual) perceptual demonstrative judgement That raccoon is wounded thought by me when I am confronted by a raccoon prowling in my backyard. According to the first, object-dependent view, the demonstrative content of my thought is tied so tightly to the actual raccoon

\footnotetext{
${ }^{4}$ Cf. Searle's (1983) causally self-referential contents, criticized by Burge (1991) and McDowell (1991). As Burge points out (p. 211n2), it is not clear whether Searle really intends to invoke demonstrative reference to a place, since the essence of his account seems to be to restrict demonstrative reference to visual experiences. Why allow irreducible demonstrative reference to places but not objects? In fact, as Evans (1982, pp. 172-173) argues, often we can only single out a place by demonstratively referring to some object located at it.

${ }^{5}$ Cf. Burge (2010, p. 186): 'Singular reference to the informational state itself is less plausible than singular reference to the particulars in the world'.

${ }^{6}$ Examples of the former include: Evans (1982), McDowell (1977, 1984, 1986, 1991), Davies (1981a), McCulloch (1989), Crawford (1998), cf. Kaplan (1989). Examples of the latter include: Burge (1982, 1983, 1991, 2009), Bach (1982, 1987), Segal (1989), Peacocke (1981), Noonan (1986, 1991), Recanati (1993).
}

thought about by me that the content would have been different if a numerically different but qualitatively indistinguishable raccoon had appeared before me. Moreover, if no raccoon, indeed nothing at all, had been there and I had, say, suffered a brief hallucination or referential illusion, then there would have been no demonstrative content for my thought to contain and so no demonstrative thought—only the illusion or delusion that I was having such a thought. In short, according to this view, the demonstrative content of my demonstrative thought cannot remain constant across either "duplicate" or "empty" counterfactual possibilities, as I shall call them. According to the second object-independent view, however, the demonstrative content of my thought That raccoon is wounded would be unaffected by the counterfactual substitution of a duplicate raccoon or by the absence of any raccoon at all-the demonstrative content, in short, can remain constant across both duplicate and empty possibilities.

As already indicated, there are good reasons to accept the irreducibility thesis and I shall not question it here. ${ }^{7}$ What I wish to do is question the adequacy of each of the two kinds of view of demonstrative thought just described and sketch what seems to me to be a more adequate view. The most prominent exponents of the first kind of view, which I will call the 'object-dependent theory' (ODT), are Evans (1982) and McDowell (1977, 1984, 1986, 1991). The most fully worked out theory of the second kind, what I shall call the 'object-independent theory' (OIT), is Burge's (1977, 1982, 1983, 1991, 2007a, 2009) account of belief de re. Although there is much to be said for each theory, neither, to my mind, is fully satisfactory and I shall propose an alternative theory, which I call the 'property-dependent theory' (PDT). Briefly, the basic idea behind PDT it is that demonstrative content is dependent exclusively upon the observable properties of things and not their identities or metaphysical essences. When there are no objects for our perceptual demonstrative thoughts to single out there are no properties instantiated in the world to give them content; hence, in the absence of an object, when a subject is hallucinating, no perceptual demonstrative thought will be available to him. However, since duplicate objects share their observable properties, perceptual demonstrative thoughts about duplicates share their demonstrative content.

The structure of the paper is as follows. I first explain the essentials of ODT and OIT ( $\S 2$ and 3 ). I then set out PDT (§4). This leaves us with three different views regarding the nature of (visual) perceptual demonstrative thoughts. I then go on to argue that both ODT and OIT are unsatisfactory because they each fail to satisfy (different) desiderata

\footnotetext{
7 See Evans (1982), Burge (1977, 1991), and especially Austin (1990) and further footnote 38 below.
} 
that any theory of demonstrative thought should fulfil; and that since PDT can fulfil all the desiderata, it is superior (§§5 and 6).

\section{The Object-Independent Theory (OIT): Burge on De Re Belief}

Perceptual demonstrative thoughts are a subclass of "singular" or "de re" thoughts and Burge's OIT of demonstrative thought takes the form of a general theory of de re belief (1977) or "de re states and attitudes" (2009).

The key idea motivating Burge is that 'A de re belief is a belief whose correct ascription places the believer in an appropriate nonconceptual, contextual relation to the objects the belief is about' whereas 'a correct ascription of [a] de dicto belief identifies it purely by reference to a "content" all of whose semantically relevant components characterise elements in the believer's conceptual repertoire' (1977, p. 346). Though Burge is clearly sensitive to the distinction between thoughts and their ascription, in the sense that he allows that there can be de re ascriptions of de dicto attitudes (ibid., 2007a, p. 66)—called the "pseudo de re" by Kaplan (1989) — his theory postulates a parallelism between what he calls the epistemic characterisation of beliefs and the semantical characterisation of belief attributions. The logical form of an attribution mirrors the epistemic or conceptual character of the thought attributed. Semantically speaking, de dicto attributions relate thinkers to complete propositions, that is, to entities that are true or false absolutely. De re attributions relate thinkers to objects and open sentences; such ascriptions are about 'predication broadly conceived' (1977, p. 343), in the sense that they have truth values only because a context of interpretation has provided a salient object for their predicative elements (open sentences) to be applied to. ${ }^{8}$

Ralph's de dicto belief that someone is wounded is most appropriately reported by a de dicto ascription whose logical form is rendered in the following manner:

\section{1. $\mathrm{B}(\operatorname{Ralph},\ulcorner(\exists \mathrm{x})$ Wounded $(\mathrm{x})\urcorner)$.}

Ralph's de re belief, of someone in particular, that he is wounded should be reported by a de re ascription whose logical form is:

\section{2. $(\exists \mathrm{x})(\mathrm{B}($ Ralph, $<\mathrm{x}>$, $\ulcorner$ Wounded $(\mathrm{y})\urcorner))$}

and the de re ascription of Ralph's de re belief, of the raccoon under the fern, that it is wounded comes out as:

\footnotetext{
8 This view is adopted and elaborated in various different ways by Bach (1987) and Segal (1989). Burge (2009) updates the view substantially.
}

3. $\mathrm{B}($ Ralph, $<$ the raccoon under the fern $>$, $\ulcorner$ Wounded $(\mathrm{y})\urcorner)$.

A de re ascription of a (de re) belief, such as (3), relates a believer to a res and an open sentence which contains concepts under which the believer thinks of the res. The singular term in the pointed brackets is in purely referential position and is open to substitution and existential generalisation. The open sentence in the third argument place is intended to represent the intentional content of the thought and contains terms that are not open to substitution. The intentional content in the third argument place contains a primitive demonstrative element, indicated by the presence of the free variable in the open sentence that represents it, that is contextually applied to the res which is designated by the singular term in the second argument place. ${ }^{9}$ The canonical representation (3) can be roughly parsed, along the following rather barbaric vernacular lines, as: 'Ralph believes that is wounded of the raccoon under the fern'.

Epistemically speaking, the object of a Burgean de re thought, which is the proper topic for a de re ascription, is not determined entirely by the content of the thought: which object the thought is about is not simply a matter of which object satisfies or is denoted by the conceptual components of the thought; rather, the object that the thought is about is the object that the intentional content is applied to via an 'appropriate nonconceptual, contextual relation', namely, the token mental "application" (Burge 1983, 2009) or "act of reference" (Burge 1974b), by the individual thinker at a time, of the demonstrative element in the content-which, in the paradigm case of perception, is successful owing to the object causally impinging on the thinker's sense organs. ${ }^{10}$ The idea plays an essential role in fixing the truth conditions of de re thoughts: while the truth conditions of a de dicto belief are determined entirely by the completely conceptualized content of the thought all on its own, as it were, the

\footnotetext{
9 Notice that (2) and (3) do not say how Ralph is thinking of the raccoon. The free variable ' $y$ ' in the open sentence $\left\ulcorner\right.$ Wounded(y) ${ }^{\urcorner}$is the representation of a simple demonstrative such as 'this' or 'that' (or 'it'). Complex demonstratives with nouns attached that provide descriptive content, such as 'that raccoon', are represented in the following way: $\ulcorner[y] \operatorname{Raccoon}(y)\urcorner$, where the square brackets indicate the scope of the demonstrative and do not bind the free variable. So if we also wish to attribute to Ralph the concept of a raccoon under a fern we can do so in the following manner:

$\mathrm{B}$ (Ralph, <the raccoon under the fern $>$, $\ulcorner$ Wounded([y](Raccoon(y) \& Under Fern(y)) $)^{7}$,

which indicates that the object of Ralph's belief, the raccoon under the fern, is presented to Ralph as the raccoon under the fern - as it would be if Ralph gets a clear look at the animal in the forest. In such a case, the intentional content of Ralph's perceptual demonstrative belief includes the concept of being a raccoon under a fern and so we could parse this rather horribly as: Ralph believes that raccoon under the fern is wounded of the raccoon under the fern.

${ }^{10}$ Cf. Geach (1957), Chap. 15, cited by McDowell (1994) p. 105n29.
} 
truth conditions of de re beliefs are determined contextually by these token mental acts of application of incompletely conceptualized intentional contents. ${ }^{11}$ That the truth conditions of $d e$ re beliefs are determined contextually makes them like predications: the intentional content of a de re belief is true of or false of objects. A de dicto belief, however, is "completely conceptualised" in the sense that everything that is relevant to determining which object the belief is about is contained in the intentional content of the thought itself-so it is altogether free of contextual-applicational elements. A de dicto belief is a relation between a believer and a closed sentence, and hence, the truth conditions for a de dicto belief are absolute: the content of the thought - a full proposition or dictum - is itself true or false independently of any context. On this view, a de dicto belief is simply any belief devoid of demonstrative or applicational elements. ${ }^{12}$

Burge's de relde dicto dichotomy is highly reminiscent of Russell's distinction between knowledge by acquaintance and knowledge by description, in the sense that it posits two fundamental ways in which thought makes contact with reality: directly and partly non-conceptually via contextually applied demonstrative or indexical concepts, on the one hand, and indirectly via non-contextual purely conceptual concepts, on the other. The key difference lies in the fact that in the former case mental reference is achieved in a context by a token mental act of, or event within, the subject, whereas in the latter reference is achieved entirely by concepts without needing any help from the subject or the context in which he is situated. I think we can safely assume that by conceptual, Burge means something very close to the relation of denotation or satisfaction that obtains between an object and a unique specification of it. Burge's act of application replaces Russell's epistemic notion of unmediated and infallible acquaintance with experiences and universals. The

\footnotetext{
11 Thoughts expressed with the use of explicit demonstrative or indexical constructions of ordinary language-'she', 'that', 'here', 'I', etc.-are not the only instances of thoughts with contextually "applied" contents. In Burge's (1973, 1977) view, many thoughts whose expression involves the use of proper names and incomplete definite descriptions will often (more often than not, in fact) include irreducibly contextual-applicational elements needed to secure reference.

12 Although this seems to be the view of 'Belief $D e R e$ ', as Burge (2007b) makes clear later, this is not perhaps entirely accurate and his current considered view is that thoughts about numbers, e.g., are $d e$ $r e$ but do not involve demonstrative or indexical elements. This fact does not affect any issue under discussion here as we are concerned exclusively with perceptual belief and Burge is clear that all such empirical thought does contain (irreducibly) demonstrative or applicational elements. It is perhaps also worth emphasizing that empty de re thoughts, where no res is successfully picked out, are still categorized by Burge (2007b) as de re rather than de dicto, or rather as "proleptically" de re, as he puts it elsewhere (Burge 2009, p. 308). See also Burge (2003b, p. 360n4)
}

major difference from Russell is here and is twofold: first, Burge's acts of applying indexical intentional contents can be to ordinary physical objects and, second, such applications can fail to be to anything, without in any way affecting the intentional content. As he says,

characterizing a de re belief as de re, requires reference to the re [sic], which may indeed be outside the Intentional content. But ... the property of being a de $r e$ belief is not in general essential to the identity of the belief. ... In my view, the Intentional side of a belief is its only side. In many cases, in my view, a belief that is in fact de re might not have been successfully referential (could have failed to be $d e$ re) and still would have remained the same belief. Moreover, the belief itself can always be individuated, or completely characterized, in terms of the Intentional content. (1991, p. 209)

That is to say, in my terms, the very same demonstrative content could have existed in an empty possibility. ${ }^{13}$ Moreover, when it comes to a duplicate possibility, a subject may have

the same belief-content in both situations. It is just that he would be making contextually different applications of that content to different entities. ... The nature of his mental state is the same. He simply bears different relations to his environment. (1982, p. 97)

In short, demonstrative thoughts are object-independent. The striking feature of Burge's theory is that it combines the object-independence of demonstrative thinking with the irreducibility thesis. It does this precisely by separating the intentional content of a demonstrative thought from its object. It is this that sets it apart from both Russell's view and the views of object-dependent theorists, such as Evans and McDowell. I shall argue later that Burge does not in fact manage successfully to combine these two elementsobject-independence and the irreducibility thesis-into a coherent whole (\$5).

Let us look in a little more detail at how Burge envisages the assignment of truth conditions to demonstrative thoughts (and de re thoughts generally). In his (1974b, 1983) formal semantics for a language containing demonstratives, the truth conditions of sentences containing demonstratives - and of thoughts with demonstrative elements-are given by conditionalized biconditionals whose antecedents specify, among other things such as the speaker (or thinker) and the time of utterance (or thought), the value assigned to

\footnotetext{
${ }^{13}$ Burge thus agrees with Searle when the latter says that 'all beliefs consist entirely in their Intentional content' (1983, p. 214) but disagrees with Searle in holding that Intentional content is not always sufficient to individuate the object of the belief. See Burge (1991) and the opening pages of Burge (1982).
} 
the free variable in the demonstrative element. Simplifying, the basic schema of such conditionalized truth conditions is something like this:

(S) If $u$ is an utterance of $\ulcorner\mathrm{Fa}\urcorner$ by person $p$ at time $t$ and $p$ refers with the demonstrative term $a$ in $u$ to $x$, then $u$ is true with respect to $p$ at $t$ if and only if $x$ is $\mathrm{F}$.

If I see a raccoon, and express my thought that it is wounded by saying 'That is wounded' (or, more naturally, 'It is wounded'), then the following is an instance of the above schema:

If $u$ is an utterance of 'That is wounded' by Ralph at 20/01/2017/noon/GMT and Ralph refers with 'That' in 'That is wounded' to $x$, then $(u$ is true with respect to Ralph at 20/01/2017/noon/GMT if and only if $x$ is wounded).

Burge is explicit that although the semantical rules 'are defined on sentences, they apply mutatis mutandis to attitude contents' $(1983$, p. 87). It would seem on the face of it to follow from this semantical rule that since no demonstrative reference is actually achieved in the antecedent here, the consequent cannot be detached in order to derive any truth conditions. So, Ralph's attempted thought here appears to have no truth conditions.

But the matter is not so straightforward. For Burge also holds that thoughts or utterances with non-denoting terms do have truth-values. Burge (1983) holds that the truth of atomic predications is contingent upon a successful demonstrative application, so that unsuccessful applications, such as Ralph's in the empty case with 'That is wounded' (or in 'That raccoon is wounded'), will fail to be true. But, now, since he adheres to bivalence (1974a, 1983), Burge then goes on to count such simple singular predications as false. Since such atomic sentences involving nonreferring singular terms are counted false in virtue of being definitely not true, it follows again by bivalence that complex sentences formed from their negation, such as 'It is not true that that (raccoon) is wounded', perhaps said or thought by Ralph after he realises he has been hallucinating, come out true. Burge (1974a, 1983) adopts a negative free logic in which there can occur irreferential singular terms-bearerless names and empty demonstratives and indexicals - and which has the appropriate restrictions on the rules of Universal Instantiation and Existential Generalisation, according to which verdicts on truth values correspond to Russell's.

But, of course, in order to have a truth-value a thought or utterance must have a truth condition. ${ }^{14}$ There is, then, a lack of clarity surrounding Burge's view of the truth conditions

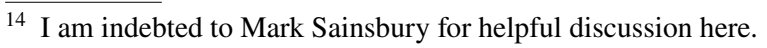

of empty demonstrative thoughts: Do they, or do they not, have truth conditions? On the one hand, his procedure of assigning truth conditions by way of conditionalized bi-conditionals suggests that they do not; on the other hand, his view that empty demonstrative thoughts are false suggests that they do. We shall return to this crucial issue below (\$5).

In the meantime, let us sum up the key features of Burge's OIT. De re thought contents contain an irreducibly indexical element (indicated by the presence of a free variable in the canonical representation of the logical form of their ascriptions) that is contextually applied by the thinker at a time in a token referential act of application. For Burge all empirical de re thoughts are thoughts with demonstrative or indexical or contextual-applicational components; de dicto thoughts are simply those that are not $d e r e$, that is, that are entirely devoid of any occurrences of indexicals. ${ }^{15}$ Burge thinks of indexicality as essentially involving a nonconceptual element, by which he means that not everything relevant to determining which object a de re thought is about is part of the intentional content of the thought. In most cases de re thoughts are not essentially $d e$ re: if the token demonstrative application had failed to refer to any object, the thought would have remained the same thought. ${ }^{16}$

The object-dependent theory holds just the opposite view of de re thoughts in which they are essentially tied to their objects and are fully conceptualised.

\section{The Object-Dependent Theory (ODT): McDowell and Evans on De Re Sense}

According to Pettit and McDowell (1986), 'one cannot properly support the claim that a state of mind is object-involving in itself by appealing to the possibility of attributing it transparently' (p. 6n18). ${ }^{17}$ Two further factors are required: that the object enter into the content of the belief and that it do so essentially. As McDowell (1984) puts it, 'contents ... are de $r e$, in the sense that they depend on the existence of the relevant res' (p. 291). Unlike Burge's view of the logical form of ascriptions of de re belief, where the res occurs outside the specification of content, on the McDowellian view, the

\footnotetext{
15 As mentioned already in note 12 , Burge (2007b, pp. 69-70) holds that some mathematical thought (as well as some second-order thought about representational content) is de re but does not include any indexical or demonstrative elements. Such de re thoughts have contents that are completely conceptualized but they (apparently) nevertheless bear a not-completely-conceptualized relation to their subject matter. Again, this aspect of his view need not concern us here.

${ }^{16}$ Burge does thinks that some thoughts, perhaps some involving 'I' and 'now', may be object-dependent.

17 Cf. McDowell (1984, p. 291) and Evans (1982, p. 73).
} 
res enters into the specification of the content and in such a way that if there is no res then there is no content to be believed, and hence, no belief. In short, the content of a de re belief is object-dependent; and since for McDowell (and Evans) intentional contents belong to the realm of Fregean sense, McDowell refers to the singular components of singular thought contents as "de re senses": modes of presentation of objects that, while not identical with the objects presented, depend on the existence of the objects. ${ }^{18}$ Burge's claims to the contrary notwithstanding, on McDowell's view Burge's account of the logical form of de re ascriptions of de re beliefs obscures, indeed falsifies, rather than mirrors their epistemic nature: 'de re attributions do not display the logical form of states with de re content' (ibid., p. 291).

This object-dependent view of singular thought is worked out in great detail and sophistication by Evans (1982). Evans's view is akin to Kaplan's (1968-1969) model of being en rapport with the object of one's thought in the sense that it involves a harmony between causal and epistemic factors. In Kaplan's model, the 'of-ness' (the causal factor) and the 'vividness' (the epistemic factor) of thoughts must coincide for the subject to have a de re thought; de re thoughts are like good photographs of people. The very large difference from Kaplan comes with the account Evans gives of the two factors.

The first, causal, factor is explained in terms of the person possessing information flowing from the object as, say, in perception (as well as indirectly in memory and testimony). The content of an informational state is given independently of the object from which the information flows and thus may be represented by an open sentence containing as many places and predicates as is required to capture the desired content. ${ }^{19}$ The second, epistemic, element is articulated in

\footnotetext{
${ }_{18}$ It is crucial to this view that there can be singular thoughts with different singular contents that nevertheless predicate the same property of the same object. See Davies (1981b, pp. $99 \mathrm{ff}$ ) for discussion of the important difference between what he calls "genuine singular reference," which is the Fregean object-dependent view of McDowell and Evans that takes contents to be Fregean senses, and what he calls "direct reference," which is the anti-Fregean view associated with Donnellan (1974) and Kaplan (1989), which takes contents to be exhausted by reference.

19 Evans's (1982, p. 125) example is a photograph of a red ball on top of a yellow square. The informational content is represented by a conjunction of open sentences: $\operatorname{Red}(\mathrm{x}) \& \operatorname{Ball}(\mathrm{x}) \&$ Yellow(y) \& Square(y) \& On Top Of(x, y). Burge (2010, pp. 184-186) criticizes the fact that Evans holds that such an informational-perceptual state could be of or about objects $a$ and $b$ without those object being singularly represented in the content. Though he does not (in Burge 2010) say so explicitly, presumably Burge's (1974b, 1977) representation would be: OnTopOf $\{[\mathrm{x}](\operatorname{Red}(\mathrm{x}) \& \operatorname{Ball}(\mathrm{x})),[\mathrm{y}]($ Yellow $(\mathrm{y}) \&$ Square(y)) $\}$. See note 9 above for explanation of this notation. The notation can be can read more informally as: That ${ }_{1}$ red ball is on top of that ${ }_{2}$ yellow square, where the subscripted demonstratives take the place of the two free variables.
}

terms of the individual having what Evans calls a "mode of identification" of the object, by which he means that the individual knows which object it is that he is receiving information from in the sense that he can identify it. There are three kinds of modes of identification: descriptive, demonstrative, and recognition-based. Very roughly, whereas the first, descriptive, mode of identification involves the agent's ability to cite facts uniquely true of the object from which the information flows, the latter two modes of identification involve more practical capacities: being able to locate the object on the basis of information from it and to being able to recognise the object when presented with it, respectively. Just as for Kaplan (1968-1969) 'of-ness' and 'vividness' must both centre on $\mathrm{x}$ for a thought component $\alpha$ to represent $\mathrm{x}$ to a subject - and so for that subject to have a thought reportable de re-so too for Evans the mode of identification must target the object from which the information derives for the subject to have a singular thought about that object. Having a mode of identification of an object involves having what Evans calls an adequate or coherent "Idea-of-anobject". Unlike Kaplan, however, Evans's account focuses on action, on what subjects can $d o$, such as locate and recognise objects, or direct their actions to the places or upon the objects that their thoughts concern. We might put the point by saying that whereas Kaplan's account is a pure "input" theory, Evans's is an "input-output" or functional theory.

The background of Evans's account of singular thought is complex. It begins (1982, Chap. 4) with the assumption that in order for a subject to have a singular thought that $a$ is $F$ the subject must know what it is for the proposition $\ulcorner a$ is $F\urcorner$ to be true. For a subject to know this he must have an Idea of the object $a$, where 'An Idea of an object is part of a conception of a world of such objects, distinguished from one another in fundamental ways' (p. 106). For any object whatever, there is the fundamental ground of difference (FGD) of that object (at a time): that which differentiates it from all other things of the same kind. One has a fundamental Idea (FI) of an object, $\delta$, when one thinks of it as the possessor of the FGD which it in fact possesses. According to Evans's account, when we have a FI of an object, $\delta$, then that can combine with our possession of the concept of being $F$, to yield direct knowledge of what it is for the proposition $\ulcorner\delta$ is $F\urcorner$ to be true. When we have a non-FI of an object, $a$, then we know what it is for the proposition $\ulcorner a$ is $F\urcorner$ to be true in virtue of knowing the truth of some pair of propositions of the forms: $\ulcorner\delta$ is $F\urcorner$ and $\ulcorner\delta=a\urcorner$. In short, 'we can take the subject's Idea-of-an-object, $a$, to consist in his knowledge of what it is for an arbitrary proposition of the form $\ulcorner\delta=a\urcorner$ to be true' (1982, p. 110). The FGD of a material object is given by its spatial location at a time (and possibly the sortal it falls under if two or more such objects can occupy the same spatio-temporal location, as in the cases of statues and chunks of marble). So, according to the foregoing, one 
has an adequate Idea of a material object either when one has a conception of it as the occupant of a particular location at a particular time or when one has knowledge of what it is for the relevant object to be (identical with) an object at a particular location in space and time (and possibly as a particular sort of thing). When a subject has a singular demonstrative thought $a$ is $F$, he will have a conception of $a$ as identical with a certain kind of object occupying a certain spatio-temporal location (1982, p. 178) ${ }^{20}$ It is this conception of $a$ as the object at such-and-such a location at suchand-such at time that provides the subject with an adequate Idea of the object. That the subject does have this conception of the object is shown by the subject's general ability to locate objects in egocentric space on the basis of information links and his general capacity to align his egocentric space with objective or allocentric space. ${ }^{21}$

It follows, on Evans's account, that if there is no object (or place) on which the subject's locating ability is uniquely targeted-if, say, he is hallucinating or a series of different objects or places present themselves to the subject without his knowledge - there will be no singular thought available to him. An Evansian mode of identification or Idea-of-anobject is effectively a McDowellian de re sense, which, as we have seen, is an object-dependent sense. A subject has a de re sense or an adequate Idea-of-an-object only if there is one object to which he is appropriately connected; that is in part what it is to have such an Idea.

This is in stark contrast to the Burgean view whereby a singular thought with intentional content is secured by way of the thinker engaging in an act of reference or application of a "mental indexical" that does not have to be successful. Such acts, for Burge (1983), are not individuated in terms of the agent successfully applying his mental indexicals: 'Applications may be either occurrent acts or continuing dispositions to occurrent acts. ... it should be noted that there may be an application without its being to any object' (p. 85: cf. 2009). As he explains, 'applications ... are individuated with an eye toward accounting for the individual's cognitive life over time. What counts as the same application depends on the individual's memory and his own sense of whether he has switched referents or not' (ibid., pp. 90-91; cf. 2009). For Evans and McDowell, of course, if an individual ends up in a situation in which he is either hallucinating or failing to track a single object his "cognitive life over time" will

\footnotetext{
${ }^{20}$ He need not actually know exactly what kind of thing the object is; he only needs to be able to discover what sort of thing it is.

21 There is some debate over how to interpret the first ability. Peacocke $(1983,1991)$ argues that the subject need only have the general ability to exploit information links in favourable circumstances and that he need not be able actually to locate the object in every case in which he has a demonstrative thought. For a contrary view see, McDowell (1990). Campbell (1997) is also relevant.
}

not consist in any singular thoughts whatever else it might consist in (such as existence/non-existence-indifferent purely descriptive or general thoughts [Davies 1981b, p. 98]).

Turning now to questions about truth conditions and truth values, Evans remarks against Frege that 'Where thoughts, or beliefs, are concerned, surely failing to have the value True just is having the value false' (1982, p. 25). Burge, of course, unlike Frege, agrees with this; his negative fee logic is constructed with just such an assumption in mind. Since both sides agree, against Frege, on the relation between thoughts and truth-values, yet Burge rejects object-dependence while Evans and McDowell embrace it, their disagreement about empty singular thoughts can only be over the relation between thoughts and truth conditions. Though Burge never squarely confronts the issue, because it is buried in his primary project of constructing a semantics and logic for indexical languages containing empty singular terms, he appears prepared to allow for thoughts without truth conditions. ${ }^{22}$ The object-dependent theorist, by contrast, does not allow this. On Evans's and McDowell's Fregean view, the intentional content of a thought is essentially truth conditional because the content of a thought is precisely something that represents the world as being a certain way: the intentional content of a thought lays down correctness conditions that the world must meet in order for the thought to be true. Unlike Burge, they adopt (or at any rate, Evans at least does) the Fregean view that since an atomic sentence containing an empty singular term does not express a thought, because it has no truth conditions, it cannot have a truth value (Evans 1982, p. 25; McDowell 1982, p. 304). For Burge, recall, such sentences are simply assigned the value false in virtue of being not true (in adherence with bivalence). That the debate here is over truth conditions rather than truth values is further illustrated by the fact that the only empty singular terms Evans is willing to countenance as fit to figure in sentences that can express genuine thoughts are those that are associated with clear descriptive conditions, namely, what he calls "descriptive names" $(1982, \S \S 1.7,1.8,2.3)$. This is because only with this kind of empty singular term can sentences embedding them have determinate truth conditions, and hence, express thoughts. Evans adopts a negative free logic akin to Burge's but in which only atomic sentences containing descriptive names are counted false. We shall return to the issue of truth conditions below $(\$ 5)$.

\footnotetext{
${ }^{22}$ We saw earlier (\$2) that he seems also to want to say that empty singular thoughts do have truth conditions because they have truthvalues. This puzzle will be resolved in $\S 5$ below.
} 


\section{The Property-Dependent Theory (PDT)}

Having set out OIT and ODT, I turn now to PDT. I begin with the idea that the intentional content of a perceptual demonstrative thought-an occurrent, conscious perceptual belief-about a material object is made available by the perceptual experience of the object upon which the thought is based. When I think to myself That painting is fauvist the perceptual demonstrative mode of presentation of the painting essentially involves my visual experience of the painting. If I were unable to see the painting, with all its vibrant colours, I would be unable to have the perceptual belief on the basis of which I arrive at the judgement that it is a fauvist painting. To say that the intentional content of my perceptual belief is "made available by" or "involves" the visual experience upon which it is based is simply to say that the phenomenal character of my visual experience of the painting-how the painting is presented to me, how it appears to me-in part determines the content of my perceptual belief or judgement. More specifically, it is the particular aspects of my visual experience's phenomenal character, its phenomenal features (Langsam 1997), such as the painting's appearing red to me, that in part determine the content of my perceptual belief. This particular "appearance of red" is an instantiation of the phenomenal feature of redness and it in part determines the content of my belief that that painting is fauvist. It is, of course, a vexing question exactly what this relation between sense experience and cognition is. Is the phenomenal character of the visual experience itself part of, or contained in, the intentional content of the belief? ${ }^{23}$ Or is it rather that the conscious character of the perceptual experience, while not itself literally part of the content of the belief or judgement, nevertheless somehow gives rise to it? ${ }^{24}$ Since the conflict between OIT, ODT and PDT does not turn on the answers to these questions I shall leave them moot. Everyone agrees that it is the perceptual experience of an object that provides the perceptual demonstrative way of thinking of the object that in part constitutes the intentional content of the perceptual demonstrative thought or judgement about the object.

The fundamental differences between OIT, ODT and PDT stem, I maintain, from prior views, often tacitly presupposed, about the nature of sense experience itself rather than its precise relation to cognition. To see this, consider Martin's (1997) useful taxonomy of approaches to sense experience: the subjectivist view, the intentional view, and the naüve realist view. Briefly, subjectivist or 'qualia'-based views treat the phenomenal or qualitative or conscious character

${ }^{23}$ Searle (1983) and McGinn (1982) hold such a view. For arguments against such a view see Peacocke $(1986,1989)$.

24 As, e.g., in Evans (1982). of experience as involving objects or features whose existence depends upon the subject's awareness of them. The classic example of a subjectivist view is, of course, the sense-datum theory of experience according to which the immediate objects of experience are (possibly non-physical) entities that are internal mental surrogates for the perceived external objects and that possess qualities that correspond to the qualities of the indirectly perceived external objects. Other subjectivist views that reject an 'act-object' analysis of perception, such as the adverbial theory, dispense with mental intermediaries such as sense-data, holding that the experience, or the act of experiencing, itself possesses the phenomenal features in question. The intentional view assimilates experience to intentional states, particularly propositional attitudes such as belief and judgement, holding that the phenomenal character of perceptual experience is constituted and exhausted by its representational content. The phenomenal character of experience is seen as nothing more than the way experience represents the world as being and is individuated by the objects and qualities that must be present in the world for the content of the experience to be correct. On this view, perceptual experiences are said to have a representational content determined by their "satisfaction conditions" (Searle 1983) or "correctness conditions" (Peacocke 1992) or "veridicality conditions" (Burge 2005, 2010). The naïve or direct realist view takes the phenomenal character of experience to be partly constituted by the actual external objects of perception and those of their qualities that are manifest to us when we perceive them. The external object and its observable properties partly determine the phenomenal character of perceptual experience in the sense that one could not be in such a conscious state of mind were one not perceiving the object in question and its observable properties. The observable properties of the perceived object directly present themselves to us and thus constitute the phenomenal features of our sense experience. John Campbell (2002) calls this view the "Relational View of Experience" because the "experience of an object is a simple relation holding between perceiver and object' and 'the qualitative character of the experience is constituted by the qualitative character of the scene perceived' (pp. 114-115).

This three-fold taxonomy is particularly apposite for our concerns since it categorises various views of perceptual experience in part by how they answer the question whether the phenomenal character of experience can have the phenomenal features it does without the objects or qualities in virtue of which those features are individuated actually being instantiated. According to both the subjectivist and naïve realist (or relational) approaches, the qualities in virtue of which the phenomenal character of experience is individuated must actually be realised or instantiated in order for the experience to have that phenomenal character. According to the sense-datum version of the subjectivist theory, these 
qualities are instantiated by internal mental entities whose existence depends on the awareness of the subject; according to naïve realism or relationalism these qualities are simply the properties of ordinary objects in the world (whose existence does not depend on the awareness of the subject). On the intentional theory, however, an experience may be an experience as of some object or quality without that quality actually existing or being realised, since the experience is seen as a representation of the object or quality in question and representations, in order to be representations, do not require the objects they represent to exist. Thus Dretske (1995), a well-known advocate of the intentional theory, speaks of a subject's consciousness or awareness of the properties of pinkness and being rat-shaped when he is hallucinating or dreaming of pink rats. Of these properties he says, 'They are the same properties ... as those who see pink rats are aware of' and that 'What makes a creature conscious of these properties is the same thing that makes a person who sees pink rats conscious of them: an internal state that represents something to be pink and rat-shaped' (p. 102) ${ }^{25}$ Unlike the subjectivist and naïve realist, the intentionalist has it that one can be aware of, be conscious of, objects and properties even when these properties are not in fact instantiated; in fact, even when they are instantiated, one is conscious of them in virtue of harbouring an internal state that represents them to oneself. Importantly for our purposes, however, the subjectivist and the intentionalist agree, against the naïve realist, that the hallucinatory experience as of a pink rat is of the same conscious or phenomenal character as a veridical perceptual experience of an actual pink rat.

The subjectivist view, especially in the form of the sensedatum theory, is largely out of favour these days; its position has been usurped by the intentional theory. ${ }^{26}$ Whether this is a good thing is of no great moment for present purposes, for what is of interest is what subjectivism shares with intentionalism, namely, as was just stated, that the phenomenal character of veridical perception is the same as that of matching hallucinatory experience. Since the intentional theory preserves this element of the subjectivist theory without the latter's notorious attendant problems, and since it has become more dominant in recent discussions of perception, I will set out the debate as one between the intentionalist and the näive realist; though in so far as this debate over the nature of experience has ramifications for the debate over the nature of demonstrative thought, which is our primary concern, one could just as well juxtapose näive realism and subjectivism.

\footnotetext{
25 See also Harman (1990).

26 Jackson (1977), however, defends a sense-data theory; see also the "sensational properties" of Peacocke (1983).
}

After remarking on the fact that the intentional theorist and the näive realist both agree, against the subjectivist, that it is the normal external objects of perception that are the things "before the mind" - as opposed to the internal awareness-dependent features of the subjectivist-Martin notes that the disagreement between the two theorists is over the way in which the external objects of perception are before the mind:

The näive realist thinks of this relationally: the objects are part of the relational state of affairs which comprises perceptual experience. The intentional theorist denies this relational character. Experience is rather quasi-relational: it has a character such that it is as if the objects of perception are before the mind, but they are not required to be so in order for one to be in this state. (1997, p. 85; cf. Martin 2002)

Though Martin does not discuss the matter, one version of the näive realist or relational view that the phenomenal features of perceptual experience are relations between material objects and minds is the Theory of Appearing (Alston 1999; Langsam 1997). The Theory of Appearing is so-called because it construes the relation in question as that of a material object's appearing a certain way to a subject and takes the relation of an object's appearing a certain way to a subject as what is most fundamental to the nature of perceptual experience. Moreover, according to the Theory of Appearing, the appearing relation is primitive: it is irreducible to allegedly more fundamental relations or properties, such as causation or tendencies to believe. ${ }^{27}$ It is this version of näive realism with which I am concerned.

As I view the matter, the näive realist or relationalist, unlike the intentionalist, sees perception as fundamentally different from intentional states such as belief and judgement, in the sense that perception presents the world to us rather than represents it to us (cf. Travis 2004). In saying that sense experience presents external material objects to a subject I mean that such objects appear a certain way to a subject. To say that in sense perception a certain object appears a certain way to a subject is to say that, unlike intentional states such as belief, perceptual experiences give us direct access or direct awareness of the object. ${ }^{28}$ Such direct awareness is the converse of the appearing relation: to say that a subject is directly aware of an object's being a certain way is to say that that object appears a certain way to him. In perception, as opposed to belief, the external world itself intrudes into our conscious awareness. So I maintain, with

\footnotetext{
${ }^{27}$ Cf. Campbell (2002, pp. 117-118): 'on this view, the relation "S perceives O" is taken as primitive: it is not to be analyzed in some such terms as "O causes $\mathrm{S}$ to have an experiential content as of something's being F"'.

${ }^{28}$ Cf. Searle (1983, p. 46), Alston (1999), Campbell (2002).
} 
the Theory of Appearing, that what is most fundamental to perceptual experience is certain objects' appearing in certain ways to a perceiver. It is highly plausible that this is why perceptual experience is so much more fine grained than (non-perceptual) belief. The 'sensuous specificity of perceptual experience' (McDowell 1994, p. 60n17)—what is sometimes called its analogue character (Peacocke 1992) is conspicuously absent from (non-perceptual) belief and this is because it is a direct result of the impact on our senses of the myriad manifest features of objective reality. ${ }^{29}$

The relational character of sense experience commits the näive realist to rejecting the view, shared by the subjectivist and the intentionalist, that experience forms a common kind between perception and hallucination. Since the phenomenal character of perceptual experience is partly constituted by the manifest properties of the external material objects of perception, if there are no such objects in which any such properties are instantiated, as in hallucination, then the subject cannot be having a genuine perceptual experience, whatever else he may be having. For the näive realist, there is nothing more in common between veridical perceptions and illusory or hallucinatory experiences than that they are indistinguishable for the subject who has them. Its appearing or looking to Roxanne as if there is a fauvist painting before her-her being subject to an appearance of a fauvist painting before her-does not describe a single kind of experiential state of mind present in both perception and hallucination. Näive realism is in this sense committed to a kind of "disjunctivism" about experience: the state of its looking to you as if there is a fauvist painting before you is constituted by an exclusive disjunction of distinct types of mental states: either one is in a state of veridical perception, which is an essentially relational state of affairs involving the very properties of the object perceived, or one is in a state that is not a veridical perception but is indistinguishable from one. ${ }^{30}$

It is this näive realist or relational view of perception, with its attendant committal to disjunctivism, which is the first motivation driving PDT. ${ }^{31}$

The second intuition motivating PDT is a further "näive" thesis about perceptual experience; it is the near platitude that objects present themselves to us by way of their

\footnotetext{
${ }^{29}$ See Alston (1999) for a strong case in favour of the Theory of Appearing and Travis (2004) for an influential attack on the intentional theory.

30 There is debate, which we need not consider here, about how best to formulate disjunctivism. For discussion, see Snowdon (19801981), 1990, McDowell (1982, 1986), Child (1994), Millar (1996) and Martin (1997). Putnam (1994) also advocates a kind of naive realism-cum-disjunctivism that he calls natural realism (apparently after a remark of William James's). The seeds of disjunctivism can be found in Austin (1962, ch. 5, esp. point \#5).

31 Burge (2005) criticizes disjunctivism. Campbell (2010) and Travis (2011) defend it against Burge's attack.
}

qualitative properties: their colours, shapes, textures and smells-their "manifest" qualities, as I have been calling them-and not by way of their individual metaphysical or scientific essences, such as being numerically identical with ... or having the chemical microstructure .... Our psychologies have been designed in such a way that our perceptual systems detect the qualitative properties of things and not their haeccieties in so far as haeccieties are not qualitative but involve the very identity or "quiddity" of things and stuffs. Perceptual experience is directed towards particulars, of course, but it is so directed only via the universal features they instantiate and that are presented to us in our experience of them. These properties of which we are or can become aware through perceptual experience, and on the basis of which we come to have demonstrative thoughts or form demonstrative judgements, could have been instantiated by numerically distinct things without the phenomenal character of our experiences being any different. Perceptual experience is, in short, a purely qualitative affair: we are perceptually aware or conscious only of the qualitative features of external objects.

So the kind of disjunctivism that this version of näive realism embraces is importantly different from the kind of disjunctivism found in writers such as McDowell (1986), Child (1994), and Martin (1997, 2002). According to Child (p. 153), the very identity of the object perceived enters into a specification of the intrinsic phenomenal character of the perceptual experience of the object; he remarks that the disjunctive view of experience is a 'direct analogue' (p. 146) of the object-dependent view of singular thought. In contrast to these theorists, the kind of näive realism and disjunctivism that the property-dependent theory of demonstrative thought presupposes is one according to which the identity of the object perceived does not enter into the phenomenal character of the experience; only the observable properties of the object do. This is why I emphasise that the version of näive realism that PDT presupposes is a version of the Theory of Appearing. Since the phenomenal character of sense experience is essentially a matter of an object's appearing a certain way to a subject, and an object's very identity, its haecciety, cannot appear to a subject, an object's identity cannot enter into the individuation of the phenomenal character of perceptual experience. $^{32}$

\footnotetext{
${ }^{32}$ Cf. Crawford (2003), §III) where the distinction between psychologically discriminable qualitative properties and psychologically indiscriminable metaphysical essences or haeccieties is drawn in the context of the broader debate between internalism and externalism about mental content, in particular in the context of the debate between Fodor (1987) and Burge (1989) over whether Twin-Earth twins belong so the same natural kind for the purposes of psychological explanation.
} 
Since the qualitative features that are perceptually presented to us in experience are objective properties of things in the environment external to the thinking and acting subject, PDT is a version of externalism, in particular, a version of what Davies (1998) calls constitutive externalism: namely, 'that the fundamental philosophical account of what it is for an individual to have [a mental property] does need to advert to the individual's physical or social environment' (p. 327). The features of the environment that such an account needs to advert to are, according to PDT, the observable properties that objects and stuffs in the environment make manifest to us by their perceptual presence-such as looking red, feeling rough, or having a waterish appearance-and not the objects' or stuffs' haeccieties-such as being identical with ... or having the chemical microstructure .... The intuitive idea is that if a subject is having an hallucination of a particular object and no particular object is presenting itself to that subject, then no features of the world are being presented to the subject in any perceptual experience, and hence, nothing is there to provide a perceptual demonstrative way of thinking that could constitute any demonstrative content that might figure in any perceptual demonstrative thought—but, since in a veridical perceptual experience in which the properties of an object are presented to a perceiver, such properties might have been instantiated by different things, in a counterfactual situation in which duplicate objects present themselves to the subject by way of instantiating the very same properties, the demonstrative content of the subject's demonstrative thought is the same as it would be in his actual situation; it is just that the demonstrative content of his thought would be about or related to a different object. PDT is, in short, a form of what one might call property-dependent externalism.

In sum, PDT has three guiding principles. The first is the theory-of-appearing version of the naïve or direct realist relational view of perceptual experience. The second is the essentially qualitative nature of sense experience. The third, discussion of which opened this section, is one shared by all theorists of demonstrative thought: namely, that it is the perceptual experience of an object that makes available the perceptual demonstrative way of thinking of the object.

According to the first principle, when no perceptually presented properties are externally instantiated before a subject and impinging upon him-if he is hallucinating, say-the subject cannot be having a perceptual experience. By the third principle, our subject cannot be having a thought with any perceptual demonstrative content. To this extent PDT is in accord with ODT and in conflict with OIT over the empty case. Consider now the duplicate case. Our first, naïve realist principle, together with our second principle about the essentially qualitative nature of sense experience, imply that when the qualitative nature of a subject's environment is held constant but the identities of the objects in which the qualities are instantiated are varied there is no change in the phenomenal character of his sense experience. Again, given our third principle about the relation between perceptual content and demonstrative thought content, we are led to the view that the demonstrative content of our subject's thought remains unaltered as well. In this case, PDT concurs with OIT against ODT.

In the literature on the intentional content of perceptual demonstrative thought one finds two sorts of position. The first-OIT_-has it that the intentional content remains constant across duplicate situations, in which numerically distinct but qualitatively identical objects are perceptually presented to the subject, and-most importantlyacross empty situations, in which no objects are presented (because, say, the subject is hallucinating). So, according to OIT, the intentional content of perceptual demonstrative thoughts about particulars must be provided by something other than the perceptual presence of the instantiated properties of the objects themselves; otherwise there could be no content in the empty case. This means that OIT is committed either to subjectivism or intentionalism about the content of perceptual experience; for only these views allow there to be any perceptual content when the qualities in terms of which the perceptual content is individuated are absent. It is not always clear just what OIT takes the intentional content of perceptual demonstrative thoughts to be provided by; whether it is some kind of subjective awareness-dependent features of experience or rather special kinds of representations. Burge (1991, 2005, 2010) defends an intentionalist approach to perceptual experience. Bach (1987) seems to adopt a subjectivist approach. And Peacocke (1992, 1993; cf. 1986, 1989) defends a mixture of subjectivism and intentionalism. I cannot canvass all the extant, let alone possible, versions of OIT. Suffice it to say that however the notion of perceptual demonstrative content is cashed out by OIT, it is committed to the rejection of the theory-of-appearing version of näive realism and to acceptance of some form of subjectivism or intentionalism about perceptual experience.

The second position-ODT-has it that the intentional content of a perceptual demonstrative thought is so intimately tied to its object that its intentional content cannot remain constant even across duplicate situations. What account of the nature of perceptual experience is this view committed to? McDowell seems to advocate a kind of naive or direct realism-cum-disjunctivism about perceptual experience (see especially McDowell 1986); it is, moreover, a naive realism according to which the external material object of perceptual experience itself enters into the individuation of the content of the perceptual experience (Child 1994 seems also to hold this view). Evans, however, appears to differ from McDowell in both respects. For, first, he appears to advocate an intentional 
theory of perception (1982, p. 226) and, second, as we saw above, he holds that the (non-conceptual) content of perceptual experience, or what he calls the informational content embodied in a demonstrative thought (more generally, in any information-based particular-thought of which the demonstrative is but one variety), is individuated in a non-object-dependent way by an open sentence. ${ }^{33}$ So, according to one version of this second position, the perceptual content of perceptual experience and the intentional content of perceptual demonstrative beliefs are both object-dependent. According to the other, the perceptual content of experience is not object-dependent but perceptual demonstrative belief content is. ${ }^{34}$ The property-dependent externalism that I favour rejects both these views holding that neither the content of perceptual experience nor the content of perceptual demonstrative thoughts is object-dependent.

The impression one gets from the literature is that the available options are twofold: either a form of externalism in which content is tied to the very existence and identity of objects or a form of internalism according to which content is tied to neither. ${ }^{35}$ I suggest that both views are too extreme and that we can gratify the externalist desire for a more intimate and direct relation between mind and world while at the same time paying homage to the internalist intuition that the very numerical essence of objects, their identity, does not enter into the nature of perceptual demonstrative content. To invoke Peacocke's (1993, p. 213) metaphor, the identity of objects is "bleached out" but since the residue that remains behind is partly constituted by the objective properties of the objects detected in perception it does not follow that perceptual demonstrative thoughts are possible in the absence of any object at all.

The position I am recommending - the idea that a perceptual demonstrative sense or mode of presentation can present different semantic values, to put it in Fregean terms, is compatible with the idea that when there is no semantic value

\footnotetext{
33 See note 19 above.

34 Davies $(1992,1996)$ also holds the second version—or, at least, he holds that perceptual content is non-singular, existentially quantified content, whereas perceptual belief content is singular. Burge (2005, pp. 67-68 n6, 2010) criticizes views according to which perceptual content is non-singular (existentially quantified content, e.g.) and argues that perceptual content always contains singular representational elements, though those singular (or de re) demonstrative-applicational elements are, as we have seen, object-independent. See also note 19 above.

35 It is only a form of internalism, for Burge's OIT of course has externalist (or "anti-individualist") aspects, as he makes clear in Burge (1982, 2003b).
}

there is no sense-is, of course, inconsistent with a central tenet of ODT, namely, the role of truth conditions in individuating the content of thought. But this is not, as it stands, an objection to the proposal for it is one of the very things in dispute. Following Davies (1998), we can say that when it comes to perceptual demonstrative thoughts (and possibly other indexical thoughts), OIT and PDT draw a distinction between the content and the aboutness of thoughts that ODT does not. The content of a thought is its mental component and the aboutness of the thought is an extra-mental relation that the content bears to its object (cf. Burge 1982). The truth conditional semantics of a perceptual demonstrative thought is a combination of content and aboutness. The aboutness of a thought obviously determines its truth conditions: different aboutness relation, different truth conditions; different truth conditions, different thought. According to OIT and PDT, however, the fact that two thoughts have different truth conditions, due to their differing aboutness relations, does not mean that they have different contents, that is, that they are different in any mental respect. Since ODT construes content, the mental aspect of thoughts, as essentially representational, that is, truth conditional, it collapses the distinction between content and aboutness. If two thoughts are different because they have different truth conditions then they must have different contents; they must genuinely differ in their mental aspects. Given the dispute over whether there is any distinction between content and aboutness, all that should be assumed in advance is that is all genuine thoughts have truth conditions, that is, that all genuine thought is a combination of content and aboutness. This assumption is preserved by PDT and is in part why it can reject the "different object, different content" doctrine while at the same time uphold the "no object, no content" doctrine. In rejecting the former doctrine, however, it must reject ODT's truth conditional approach to the content of perceptual demonstrative thought.

Obviously, a great deal more needs to be said about PDT. But I have sketched out in some detail what I hope are cogent considerations in its favour, indicating the general thrust of the position, with a view to offering it as a serious contender worthy of further investigation and development. The rest of this paper is given over to showing that PDT, even in its somewhat embryonic form, is already more adequate than both ODT and OIT. The strategy I shall pursue in defence of PDT is this. There are various conditions of adequacy that it is incumbent on any theory of singular thought to fulfil. Each of ODT and OIT satisfy certain (different) ones at the expense of not satisfying others; in this sense each theory grasps it own particular nettle. PDT satisfies all of 
the important desiderata and in so doing grasps fewer nettles-so it should be accepted, or at least viewed as superior to OIT and ODT.

\section{Truth Conditions and the Intentional Content of Perceptual Demonstrative Thoughts: Against OIT}

First and foremost among these desiderata is the principle that thoughts have truth conditions. Thoughts, by their very nature, represent things as being a certain way and are true or false according to whether things are as they represent them to be. We can call this the truth condition constraint (TCC). The second is that perceptual demonstrative content must be something of which the subject is or can become aware because of its essential dependence on perceptual experience. Call this the awareness constraint (AC). The third desideratum is that any project that focuses on truth conditions in order to give an account of intentional content should explicate those truth conditions in a way that reflects the manner in which the subject of the thought grasps that content and that is consistent with his mental abilities. The truth conditions of the thought must be given in a way that displays the way in which the content is grasped by the thinker of the thought. This is the fidelity constraint (FC) ${ }^{36}$ TCC, AC and FC figure prominently throughout Evans (1982) and are used in tandem with great force in criticising competing theories. ${ }^{37}$ Restricting ourselves to perceptual demonstrative singular thoughts, it is certainly true that, if accepted, the above principles seriously constrain any attempt to specify the content of singular thoughts. For a variety of reasons that I shall not rehearse here, but which were touched upon briefly at the

\footnotetext{
36 Thanks to my colleague Thomas Uebel for suggesting the name. The analogue of FC in Davidsonain truth-theoretic semantics is the requirement that the theorems ("T-sentences") generated by the theory of meaning be interpretive, which in turn effectively requires their right-hand sides to be as near to homophonic translations of their left-hand sides as possible. As we will see presently, Burge advocates such homophony for the case of demonstrative sentences.

37 Evans, of course, argues for more than these three principles. He thinks that a correct theory of perceptual demonstrative thought must further respect what he calls Russell's Principle (RP): namely, 'that in order to be thinking about an object or to make a judgement about an object, one must know which object is in question-one must know which object it is that one is thinking about' (1982, p. 65). Unlike the three principles, which are widely accepted, RP is surrounded by controversy and adherence to it is supposed to be what is so distinctive (and allegedly implausible) about Evans's theory. I do not accept RP. For criticism of RP, see Burge (2010, pp. 191-193).
}

outset, FC, for example, rules out descriptive reductions of singular thought. ${ }^{38}$

Burge is explicit in accepting both TCC and FC. He says, for example, that 'The representational contents of thoughts are truth conditions that may or may not be fulfilled by the world' (2009, p. 286).$^{39}$ With respect to FC and demonstrative thoughts specifically, he says (1991, pp. 198-99) that.

A project that reflects on truth conditions in order to give an account of Intentional mental states ... is subject to a certain constraint. It must say something plausible about how the objects that the Intentional state refers to are presented to the thinker. ... So in giving an account of the satisfaction conditions of the use of a demonstrative that picks out a physical object, one cannot simply cite the physical object as the Intentional Content. ... [I]t is obvious that in using the demonstrative one thinks of the object from a certain perspective... Some aspect of one's mental state or perspective is relevant to picking out the object. And this aspect must be cited if one is successfully to characterize Intentional content.

For Burge, FC is 'uncontroversial' and 'helps define the project of characterising Intentional states' (loc. cit.). In light of it, he offers the following schema for the truth-conditional explication of the content of demonstrative statements and thoughts (p. 200). 'That $F$ is $G$ ' is true if and only if:

$\left(a^{\prime}\right)$ that $F$ is $G$ [where one indicates the relevant $F$, and where 'that $F$ ' is not only used, but stands for the mode of indication used in the statement (or visual experience) whose truth conditions are being given].

\footnotetext{
38 As mentioned earlier, a subject having the demonstrative thought That is a raccoon need not be, and probably is not, thinking about causation or his own visual experiences; he needn't employ and need not even posses these concepts in order to have the thought. Moreover, such contents are simply intuitively extremely implausible to attribute to a creature even with the requisite conceptual capacities in certain contexts-as, for instance, when the creature is looking directly at the thing in question (see Evans 1982, passim, but esp. 173n44). Another, but more controversial, consideration against descriptive reduction deploys Fregean considerations of cognitive significance: it is (alleged to be) possible for a subject to believe a demonstrative content without believing, indeed while disbelieving, any descriptive content proposed to be equivalent to the demonstrative content in question, thus (allegedly) demonstrating that they are not the same content. See Evans (1981) and Burge (1977, 1991).

39 TCC is taken by Burge (2007c, pp. 179-180) to be necessarily true and knowable a priori. For similar statements, see Burge (1991), Burge (2010, pp. 38, 45, 191-192) and Burge (2011, p. 52). One of his criticisms of Evans is that 'the acceptable idea that propositional representational contents are conditions on truth is transmuted into the more dubious formulation ... that thinking a thought of the form a is G entails "knowing what it is to be the case that" a is G' (2010, pp. 191-192).
} 
Burge comments on this explication: 'the Intentional content does not include any physical object that is actually picked out ... The satisfaction conditions require that there be a relevant demonstrated object if the Intentional content is to be true' (p. 211n4). This gloss seems intended to show, albeit rather sketchily, how Burge's adherence to TCC and FC — part of his philosophy of mind and epistemology — is consonant with his formal semantics for a natural language containing demonstratives - part of his philosophy of language_discussed earlier. At first sight, however, it is hard to see how it can be. Recall that the very essence of Burge's view is precisely that the intentional content of a demonstrative thought is not truth conditional; the intentional content of such a thought is represented, in a canonical statement of its logical form, by an open sentence whose free variable represents the application of the content to the relevant object. This captures the idea that demonstrative content can remain constant across duplicate and empty situations. How, then, can Burge claim adherence to a project whereby demonstrative content is explicated by way of a specification of truth conditions? Surely a truth conditional explication of irreducibly demonstrative intentional content ties the content inextricably to the object of thought.

There is a sense in which there is a real conflict here and a sense in which there is not; further, this is due to the difference between the duplicate and the empty situation. Turning to the positive point first, let us focus on the normal case in which demonstrative reference is successful. What Burge may have in mind is that the intentional content of a particular demonstrative thought can be explicated truth conditionally even though that content is not truth-conditional. Less paradoxically, the right hand side of the biconditional, which displays the intentional content of the thought by giving its truth conditions, is to be read in such a way that, although 'That $F$ is $G$ ' is a closed sentence, the demonstrative element 'That F' consists of two separate parts: the first an open sentence of the form ' $x$ is $F$ ' that represents the whole intentional content of the thought, its mental aspect, and the second the object to which the open sentence is applied. Both these elements are present in the right hand side of the biconditional: the intentional content associated with the open sentence is present in the truth conditions along with the object to which it is applied. So the reason why one can display the intentional content of a successful demonstrative thought by giving its truth conditions in the special way illustrated by ( $\left.a^{\prime}\right)$, even though that intentional content is not itself truth conditional, is that the intentional content is, as it were, "part of" those truth conditions without being identical with them (because the object to which the content is applied is also "part of" them). This is how TCC is consistent with an object-independent theory of perceptual demonstrative thought, that is, with a theory that does not tie intentional content to the identity of the object of thought. To this extent OIT can abide by TCC.
This is not, however, entirely satisfactory, which brings me to the second, negative point. It certainly seems that in the empty case one cannot display the intentional content by giving the truth conditions in this special way because it appears that there are no truth conditions to be given. There can be no bracketed off-stage direction, involving a pointing to an object, a pointing that contributes to the specification of truth conditions, because there is no such object to be pointed to! In such a case, the right hand side of the biconditional is left as an incomplete, uninterpreted dangler unable to display intentional content truth conditionally because unable to display any truth conditions. This seems to be backed up by the earlier discussion of Burge's formal semantics for a language containing demonstratives, in which assignments of truth conditions are-or at any rate, seem to be-conditional upon successful demonstrative applications. In the empty case, since there is no object netted by the act of demonstrative application, we are unable to detach the biconditional consequent of the overall conditional in order to derive any truth conditions. ${ }^{40}$

We need to be careful how we interpret this, however. The attempted or putative thought, expressed with an utterance of 'That F is G', will not have any truth conditions and therefore cannot be true. This leaves open the question whether it is false. As we have seen, Burge (1974a, 1983) wants to say that empty demonstrative thoughts are false because they are not true. So even though such empty thoughts have no truth conditions they do have falsity conditions; and their falsity conditions include the case where they are simply not true. But this is a very unusual, indeed rather artificial, notion of falsity. Normally, something, some representation, such as a sentence or proposition or belief, is false because what it says is false; it is false because its content is false. This is why we do not normally or literally say non-representations are false (or true, for that matter): we do not say, for example, that the moon, or Whistler Mountain, is false (or true). "Mere objects" such as these cannot have truth-values because they do not say anything, they have no content, they are not representations. Not being true is not sufficient, then, for being false - or else most of the things in the universe would be false by dint of being not true. But an empty demonstrative thought does not say anything either; it has no (complete) propositional representational content. Empty demonstrative thoughts fail to represent reality as being a certain way because their demonstrative concepts fail to refer to anything for their predicative concept to apply to, so that no complete thought is successfully formed. Nothing

\footnotetext{
40 This is certainly the conclusion drawn by Larson and Segal (1995, p. 219), LePore and Ludwig (2000, p. 232) and Sainsbury (2005, p. 163) when it comes to conditionalized truth conditions involving empty demonstrations in their antecedents, though none note its application to Burge specifically.
} 
is being said or thought or claimed to be a certain way and so, really, nothing is being said or thought or claimed at all (though, to be sure, there is a failed attempt to say or think or claim something).

In reaction to this, it might be said that it does make sense to say that empty thoughts can be (and are) false even though they do not have propositional content, and this is because they, crucially unlike the moon and other mere objects, are supposed to have content in the sense that their function is to have content, to represent. When they fail to carry out this function they can plausibly be taken to be false. The moon and other mere objects, on the other hand, do not even purport to represent anything, they do not have the function of doing so. That may well be right. The crucial point to bear in mind, however, is that in allowing this we have separated conditions of semantic evaluation from representational content. We will be giving a semantic evaluation of something that has no propositional representational content. ${ }^{41}$ To be sure, this divorce of semantic evaluation-truth or falsity conditions-from content may not only be theoretically plausible but actually a part of everyday practice. ${ }^{42} \mathrm{Be}$ that as it

\footnotetext{
$\overline{41}$ This is the strategy famously pioneered by Donnellan (1974) for negative existentials in his seminal paper 'Speaking of Nothing', where he proposes that if ' $\mathrm{N}$ ' is a proper name used in predicative statements, then ' $\mathrm{N}$ does not exist' is true iff the history of those uses ends in a block (where a "block" occurs when an attempt to give a historical explanation for the use of the name fails to identify a referent in which the use is grounded). As Donnellan importantly points out, 'This rule, however, does not provide an analysis of such statements; it does not tell us what such statements mean or what propositions they express. This means that in this case we are divorcing truth conditions from meaning' (p. 25). Donnellan in fact thinks that at least some predicative statements containing bearerless proper names, such as 'Santa Claus will come tonight', fail even to express propositions and so are strictly speaking meaningless. While he does not explicitly say that negative existentials with truth conditions, in particular, do not express propositions, or say that statements that do not express propositions have truth (or falsity) conditions, there is certainly the strong suggestion that in his view there may be statements that have no meaning, that express no proposition, but which will have truth or falsity conditions. Interestingly, Burge is specially acknowledged by Donnellan for his detailed comments on the paper (p. 3n1).

${ }^{42}$ Kripke $(2011,2013)$ observes that, outside of philosophy, we do say that certain sentences containing non-referring terms are false. We say, of 'Sherlock Holmes exists', 'Vulcan is red', and the like, that they are one and all are false, even though they do not, according to Kripke, express propositions (cf. Donnellan (1974) and previous note). Kripke suggests that what we are really saying here, when we say such sentences are false, is precisely that they express no propositions. He also claims that, since the argument that such sentences do not express propositions is "fairly conclusive" (the argument being that it is impossible to say under conditions such sentences would be true) one cannot infer that they do express propositions (whatever they might be exactly) from the premise that they are false (2011, p. 68). Similarly, it would be a mistake to infer that since on Burge's view empty demonstrative thoughts have truth-values they must have propositional representational content.
}

may, the fact remains that on Burge's view, what we have in the empty case is some kind of perceptual-cognitive act or event, a demonstrative application, that has, or results in, no full propositional representational content-an act or event that Burge says is false because it is not true. The upshot is that, despite always providing a semantic evaluation, a verdict of truth or falsehood, OIT does not always provide propositional representational content, and so does not ultimately sustain TCC. Though Burge says that 'The representational contents of thoughts are truth conditions that may or may not be fulfilled by the world' $(2009$, p. 286) and claims that 'The full representational content of a perception, belief, or intention constitutes a veridicality condition' (2010, p. 38) it is totally unclear how this is supposed to be consistent with his insistence (in 1983, 1991, 2003a, 2005, 2009) on the coherence of genuine empty demonstrative thought. We are forced to conclude that despite his claims to the contrary, Burge cannot simultaneously adhere to TCC and the view that genuine perceptual demonstrative thought is possible in the absence of an object for it to home in on. ${ }^{43}$

\footnotetext{
43 Braun $(1995,2005)$ has proposed that the "semantic content" of a simple subject-predicate sentence containing a bearerless proper name, such as 'Vulcan is a planet', is an "unfilled proposition" (1995) or "gappy proposition" (2005), which is supposed to be a "propositional structure that contains an unfilled position (a "gap")' (2005, p. 599). Braun goes on to argue that such gappy propositions can have truth values and be asserted and believed. It might be though that such an account could be extended to sentences containing empty demonstratives. It seems to me that such a view would at best be merely a notational variant of Burge's view and so subject to exactly the same objection. This is because a gappy proposition no more has genuine representational, that is, truth conditional, content than Burge's failed demonstrative applications do. Like Burge, Braun provides Donnellian semantic evaluations divorced from meaning (see note 41 above) for his gappy propositions. Braun's gappy propositions do not say anything about reality, they do not represent the world as being a certain way, for there is nothing referred to by their subject terms that is being said to be any way by their predicate terms. For Braun, 'Vulcan is a planet' is false, not because what it says or claims about reality is false, not because its propositional representational content is false-it does not say or claim anything about reality or have any propositional representational content-but simply because it is not true (see especially Braun 2005, p. 463). This feature of Braun's view is somewhat disguised by his subtly equivocal use of such phrases as "proposition," "meaning", "semantic content," "semantic value," "semantic object," and "what a sentence says." On Braun's eccentric use of these phrases, when someone utters "Vulcan is a planet' "what he says" is a gappy proposition. So such sentences say something. The gappy proposition that is apparently "said" is the semantic content/value/object of the sentence, its meaning, according to Braun. This is a very attenuated and Pickwickian sense of saying something and I am not at all certain it is even coherent. One does not say or claim an object; one says or claims that something is the case. At any rate, there is another, far clearer sense of saying something, namely, saying (claiming) that something is the case, in which 'Vulcan is a planet' does not say anything: it does not say anything about anything. It makes no comment on, or claim about, any subject matter; it does not represent anything as being a certain way. But
} 
Yet, while OIT must ultimately be rejected it does not follow that we must swing, pendulum style, all the way over to ODT. For one can accept that part of the Burgean OIT in which the intentional content of demonstrative thoughts is not intrinsically truth conditional but rather comes to be associated with certain truth conditions in certain circumstances. We can also accept the view that the intentional content may be displayed by giving those truth conditions in an appropriate way without accepting the view that such an intentional content can exist in the absence of any truth conditions. The positive reason for rejecting the existence of perceptual demonstrative content in the empty case is that such content is made available by the way in which objects are perceptually presented to a perceiver. The way in which objects are presented to a perceiver is determined in part by the way they appear to the perceiver and this, in turn, is in part a matter of the observable properties manifested by those objects, properties that can be instantiated by numerically distinct objects but not by no object at all. The requirement that perceptual demonstrative thoughts have truth conditions is, in a sense, simply another way of insisting that the idea of perceptual demonstrative content is at least in part the idea of an object appearing a certain way to a subject.

So far, we have seen how a view of demonstrative content that does not tie that content to the identity of its object can fulfil the aforementioned desiderata. To summarise, the view is that every successful perceptual demonstrative thought is a combination of two things: (i) the intentional content of the thought, canonically represented by an open sentence $a$ la Burge, which corresponds to the way in which the object of thought is presented to the mind of the subject and which, in turn, is itself a matter of which observable properties are

\section{Footnote 43 (continued)}

the most natural way of understanding one of the original problems that Braun's theory of gappy propositions is supposed to solve-the problem of the proposition expressed (1995) or of meaningfulness for sentences (2005) - is precisely that 'Vulcan is a planet' does not say anything about anything, say that anything is the case, make any comment or claim, have any subject matter, represent things as being a certain way, because 'Vulcan' is an empty name, and that prevents the sentence's predicate from predicating the property of being a planet of anything. Consequently, nothing is being said to be, nothing is represented as, a planet. That is the real problem and that is what is meant by saying that 'Vulan is a planet' expresses no proposition or has no meaning. Simply positing a strange entity as the "semantic object expressed" by the sentence, and assigning it a truth-value, does nothing whatsoever to solve this problem (cf. McDowell 2005, p. 60). With respect to this issue, I cannot see that there is any significant difference between Braun's favoured gappy proposition view and the other "no proposition" view that he is sympathetic to but holds to be inferior to the gappy view. On neither view does 'Vulcan is a planet' have representational content or meaning or express a proposition in the ordinary sense. In light of this, I would urge him to give up the gappy view and subscribe to the no proposition view. manifest in the perceptual experience of the object; and (ii) the object of the thought. In this way each of TCC, AC, and $\mathrm{FC}$, and the view that perceptual demonstrative thoughts that each single out different duplicate objects may share their intentional content, can all be satisfied. However, it is an essential part of this view that in a case of a failed attempt at a perceptual demonstrative thought, due to delusion of some kind or other, there is no intentional content "remaining" left over, as it were, and so there is no such singular thought, only the illusion of one.

The possibility of this kind of position has not been recognised because it is unanimously assumed that a dual-component treatment of singular thought, according to which there is a distinction between content and aboutness (as detailed above), walks hand-in-hand with the view that the mental component of a singular thought must be capable of existing independently of any object to which it is applied. The reason for the assumption that a dual-component view of perceptual demonstrative thought must allow the possibility of empty demonstrative thoughts can only be the tacit acceptance of a subjective or intentional theory of perception, according to which the perceptual experiences that provide the demonstrative ways of thinking of objects have the character or content they do whether or not the observable properties in terms of which they are individuated are actually instantiated before the subject. It is because PDT rejects this view of perception and advocates a naive realist relational view that it can preserve the dual-component analysis even while agreeing with the object-dependent theorist that if there is no object, and so no bearer of observable properties, there is no thought.

\section{Thought and Essence: Against ODT}

I have argued that OIT should be rejected because it cannot satisfy TCC. The contest now is between ODT and PDT.

The stumbling block for the object-dependent theorist is AC: perceptual intentional content is something of which subjects can be aware. In a sense this is ironic because it amounts to saying that it is the very notion of Fregean sense construed as a way in which semantic values are presented to individuals that ultimately undoes the theory. How can this be? Well, the idea of a perceptual demonstrative mode of presentation is the idea of the way in which an object is presented to the mind of a subject by way of the subject's perceptual experience presenting the object to him. This much is common ground and, at least for those who accept the irreducibility of demonstrative content, it is nicely expressed by McDowell when he says that " "that man"-when a man is in one's field of vision - expresses a way in which a man can be presented in a Fregean Thought, made possible by the fact that the man himself is present to the mind in virtue of being 
seen' (1991, p. 218). The link between demonstrative content and subjective awareness is explicit in Evans when he remarks on the 'connection between the concept of a mode of identification and the subject's awareness' (1982, p. 83). Thought content, especially perceptual thought content, as opposed to linguistic meaning, is a psychological phenomenon to be located at the personal, conscious level of the thinking subject. It is precisely the flouting of this fact that leads Evans to take the pure causal theorist to task. Evans attacks what he calls the 'Photograph Model of mental representation of particular objects' (1982, p. 81) according to which a mental state can represent an object simply in virtue of the object playing a suitable role in its casual history. Against this, Evans objects that it invokes facts 'of which the subject himself may be quite unaware' and that it is

quite obscure how, if one mental state represents a particular object in virtue of one sort of causal relation to it, and another mental state (of the same subject) represents that object in virtue of another sort of casual relation to it, the sheer difference between the causal relations could generate a difference in content between the two mental states, given that it need not in any way impinge on the subject's awareness. (p. 83)

What I wish to glean from this criticism is that a parallel point can be made about the idea, to which the objectdependent theorist is wedded, that the numerical identities of two different duplicate objects of thought are sufficient to create a difference in content between two thoughts about them. For, to echo Evans, it is quite obscure how the sheer difference between the identities of two objects could generate a difference in content between the two perceptual demonstrative thoughts about those objects given that it need not in any way impinge on the subject's awareness.

As an illustration, consider Burge's (1982) example of Alfred and the duplicate apples. Ignoring the predicative part of the thought, the property-dependent view has it that Alfred's perceptual demonstrative thought That red apple is wholesome consists of two components: (1) the demonstrative content made available by the observable properties of the object manifest in Alfred's perceptual experience of it, represented, in a canonical thought ascription, à la Burge, by the open sentence $[y](\operatorname{Apple}(y) \& \operatorname{Red}(y))$, and (2) the actual apple-apple $1 .{ }^{44}$ Counterfactually, it might have been that this same demonstrative content was applied to a different apple- apple $_{2}$. Granted, Alfred has a different thought in the counterfactual situation in which he is perceiving apple ${ }_{2}$. This is because the truth conditions of his thought differ and truth conditions lay down a requirement that the world be a certain way for a thought to be true, irrespective of whether

$\overline{44}$ See note 9 above for how to read this notation. the worldly conditions required by the truth conditions impinge upon the conscious awareness of the subject. All this is fully consistent with Alfred's thought in the counterfactual situation having the same perceptual demonstrative content as it does in the actual situation. Indeed, not only is this consistent, but it seems to be required by the fact that perceptual content is something of which the subject is or can become aware.

A similar point about thought and the essences of objects is made is in a paper on Kripke's (1979) puzzle about belief by David Lewis (1981). Lewis takes Kripke's puzzle to show that 'Pierre does not have as an object of his belief the proposition (actually) expressed by "London is pretty". For there is a possible world which fits Pierre's beliefs perfectly-it is one of his "belief worlds"-at which that proposition is false' (p. 412). The proposition actually expressed by 'London is pretty' holds at exactly those possible worlds where the thing that is actually designated by 'London' has the property which is actually expressed by 'is pretty'. Very roughly, on Lewis's view, the content of a subject's belief is the set of possibilities consistent with what he believes; a set containing all the ways things might be for all he believes. So one way of saying what someone believes is to specify the various ways things might be for all he believes (Lewis 1986, p. 27f). Lewis describes a possible world in which there are two cities, one called 'London' that is ugly and one called 'Londres' which is pretty. The former is the actual London which has now become completely ugly and the latter is the actual Bristol with a similarly suitably different history (London has fallen into total decay and all its beautiful parts have been demolished and copies made in Bristol, in which a project of beautification has been undertaken). This possible world fits Pierre's beliefs perfectly, Lewis claims; for all Pierre knows it may very well be the world in which he lives. But the singular proposition actually expressed by 'London is pretty' is false at this world. So, Lewis concludes, Pierre cannot have that proposition as an object of his belief.

The relevance of this to my criticism of ODT is that Lewis diagnoses the error in the view that the object of Pierre's belief is the singular proposition that London is pretty as one of 'ascribing knowledge of essences that we may not in fact possess' (1981, p. 413). That is to say, since Pierre is not familiar with the essence of London (whatever that essence is exactly) it does not make sense to say that London itself enters into the individuation of the content of his belief. If Pierre was familiar with the essence of London, then the alternative possible belief world that Lewis describes would not fit Pierre's beliefs, because it would no longer be the way things might be for all he believes. Since the alternative possible world is the way things might be for all Pierre believes, since he cannot tell the difference between it and the actual world, he cannot know the essence of London. 
One need not accept Lewis's own particular possible worlds framework in order to think that there is something right about the central principle in his reasoning: namely, that the notion of the content of a subject's thought is the notion of how things might be for all he believes. AC can be seen as a specific application of this general principle to the case of perceptual belief. One need not be committed to the truth of the general principle in order to think that is has a special significance when it comes to the particular case of perceptual demonstrative beliefs. ${ }^{45}$ The principle is overwhelmingly plausible here because of the essential link between perceptual demonstrative thought and perceptual awareness. For all that Alfred is perceptually aware of it may very well be apple ${ }_{2}$ that he is thinking about. As Burge himself points out, there is a possible world in which it is apple ${ }_{2}$ that Alfred is perceptually aware of and thinking about. Since, to put it in Lewis's terms, this world "fits" Alfred's perceptual beliefs perfectly-because he cannot tell the difference between it and the actual world, because for all he is perceptually aware of it may very well be the world in which he lives-the very essence or identity of apple ${ }_{1}$ cannot enter the content of his perceptual demonstrative belief about the apple.

So, what is right about OIT is that differences between duplicates do not make for differences in demonstrative content. Whether it is apple or apple $_{2}$ that Alfred's demonstrative thought is directed at is of no consequence for the individuation of the demonstrative content of Alfred's thought that that apple is wholesome. As we have seen, however, it does not follow that the difference between there being some object that one's thought is directed at and there being nothing at all that one's thought is directed at does not make for a difference in the intentional content of one's thought. For all that Burge's (1982) remarks about duplicates not affecting the way Alfred views things show, it may very well be of great consequence to the individuation-indeed, to the very existence - of the demonstrative content of Ralph's thought that that apple is wholesome that there be an object that it is directed at. Indeed, if what I have argued is correct, it is of critical consequence.

These negative points against OIT and ODT, together with the positive proposal about the role of a naive realist or relational theory of perception (in the form of the theory of appearing) in an account of perceptual demonstrative thought, conclude my case in favour of PDT. OIT fails to satisfy the requirement that thoughts have truth conditions.

\footnotetext{
45 Indeed, Salmon (1986), Crawford (2004), Kaplan (2013) and Atkins (2017) all offer contrary (and different) solutions to Kripkestyle puzzles according to which one can have singular propositions as objects of belief. But these accounts deal only with the contents of singular beliefs whose linguistic expression involves the use of a proper name, and so none count against the application of the "no knowledge of essences" to the case of singular perceptual belief.
}

ODT fails to satisfy the requirement that intentional content be something of which the subject can be aware. In contrast, PDT satisfies both of these requirements. Part of the reason why OIT and ODT fail to be entirely adequate theories is that they do not give any importance to the distinction between the empty case and the duplicate case. Attention to the difference between these two different situations promises a more adequate theory of perceptual demonstrative thought. ${ }^{46}$

Open Access This article is distributed under the terms of the Creative Commons Attribution 4.0 International License (http://creativeco mmons.org/licenses/by/4.0/), which permits unrestricted use, distribution, and reproduction in any medium, provided you give appropriate credit to the original author(s) and the source, provide a link to the Creative Commons license, and indicate if changes were made.

\section{References}

Alston WP (1999) Back to the theory of appearing. Philos Perspect 13:181-203

Atkins P (2017) A Russellian account of suspended judgment. Synthese 194:3021-3046

Austin JL (1962) Sense and sensibilia. Oxford University Press, Oxford Austin DF (1990) What's the meaning of "this"? a puzzle about demonstrative belief. Cornell University Press, Cornell

Bach K (1982) De re belief and methodological solipsism. In: Woodfield A (ed) Thought and object. Oxford University Press, Oxford

Bach K (1987) Thought and reference. Clarendon Press, Oxford

Blackburn S (1984) Spreading the word. Clarendon Press, Oxford

Braun D (1995) Empty names. Noûs 27:449-469

Braun D (2005) Empty names, fictional names, mythical names. Noûs 39:596-631

Burge T (1973) Reference and proper names. J Philos 70:425-439

Burge T (1974a) Truth and singular terms. Noûs 8:309-325

Burge T (1974b) Demonstrative constructions, reference, and truth. J Philos 71:205-223

Burge T (1977) Belief de re. J Philos 74:338-362

Burge T (1982) Other bodies. In: Woodfield A (ed) Thought and object. Oxford University Press, Oxford

Burge T (1983) Russell's problem and intentional identity. In: Tomberlin J (ed) Agent, language, and the structure of the world. Hackett, Indianapolis

Burge T (1989) Individuation and causation in psychology. Pac Philos Q 70:303-322

Burge T (1991) Vision and intentional content. In: Lepore E, Van Gulick R (eds) John Searle and his critics. Basil Blackwell, Oxford

Burge T (2003a) Replies from Tyler Burge. In: Fápolli MJ, Romero E (eds) Meaning, basis self-knowledge, and mind. CSLI, Stanford

Burge T (2003b) 'Davidson and forms of anti-individualism: reply to Hahn'. In: Hahn M, Ramberg B (eds) Reflections and replies. Essays on the philosophy of Tyler Burge. MIT Press, Cambridge

\footnotetext{
${ }^{46}$ I am greatly indebted to Martin Davies for many formative discussions about singular thought. Some of the material from $\$ 5$ was presented at the conference The Philosophy of Tyler Burge at the University of Glasgow in June 2013 and I am grateful to the participants for helpful discussion, especially Tyler Burge, although he will most certainly strongly disagree with much of what I have said here.
} 
Burge T (2005) Disjunctivism and perceptual psychology. Philos Topics 33:1-78

Burge T (2007a) Foundations of mind. Clarendon Press, Oxford

Burge T (2007b) Postscript to 'belief de re'. In: Foundations of mind. Oxford University Press, Oxford

Burge T (2007c) Postscript to 'individualism and the mental'. In: Foundations of mind. Oxford University Press, Oxford

Burge T (2009) Five Theses on de re states and attitudes. In: Almog J, Leonardi P(eds) The philosophy of David Kaplan. Oxford University Press, Oxford

Burge T (2010) Origins of objectivity. Clarendon Press, Oxford

Burge T (2011) Disjunctivism again. Philos Explor 14:43-80

Campbell J (1997) Sense, reference, and selective attention. Proc Aristot Soc Suppl Vol 71:55-74

Campbell J (2002) Reference and consciousness. Clarendon Press, Oxford

Campbell J (2010) Demonstrative reference, the relational view of experience, and the proximality principle. In: Jeshion R (ed) New essays on singular thought. Oxford University Press, Oxford

Child W (1994) Causality, interpretation, and the mind. Clarendon Press, Oxford

Crawford S (1998) In defence of object-dependent thoughts. Proc Aristotelian Soc 98(2):201-210

Crawford S (2003) Relational properties, causal powers and psychological laws. Acta Anal 18(1-2):193-216

Crawford S (2004) Pure russellianism. Philos Pap 33(2):171-202

Davies M (1981a) Individuation and the semantics of demonstratives. J Philos Logic 11:287-310

Davies M (1981b) Meaning, quantification, necessity. Themes in philosophical logic. Routledge, London

Davies M (1992) Perceptual content and local supervenience. Proc Aristot Soc 92:21-44

Davies M (1998) Externalism, architecuralism, and epistemic warrant. In: Wright C, Smith BC, Macdonald C (eds) Knowing our own minds. Clarendon Press, Oxford

Davies M (1996) Externalism and experience. In: Clark A et al (eds) Philosophy and cognitive science. Kluwer Academic Publishers, Dordrecht

Donnellan K (1974) Speaking of nothing. Philos Rev 83:3-31

Dretske F (1995) Naturalizing the mind. MIT Press, Cambridge, MA

Evans G (1981) Understanding demonstratives. In Parret H, Bouveresse J (eds) Meaning and understanding. De Gruyter, Berlin

Evans G (1982) The varieties of reference. John McDowell (ed.). Clarendon Press, Oxford

Fodor J (1987) Psychosemantics. MIT Press, Cambridge, MA

Geach P (1957) Mental acts. Routledge and Kegan Paul, London

Harman G (1990) The intrinsic quality of experience. Philos Perspect $4: 31-52$

Jackson F (1977) Perception: a representative theory. Cambridge University Press, Cambridge

Kaplan D (1968-1969) Quantifying in. Synthese 19:178-214

Kaplan D (1989) Demonstratives. In: Almog J, Perry J, Wettstein H (eds) Themes from Kaplan. Oxford University Press, Oxford

Kaplan D (2013) De re belief. Am Philos Assoc Centen Ser 9:25-37

Kripke S (1979) A puzzle about belief. In Margalit A (ed), Meaning and use. Reidel, Dordretch. Reprinted in Salmon and Soames

Kripke S (2011) Vacuous names and fictional entities. In: Kripke S (ed) Philosophical troubles collected papers, vol 1. Oxford University Press, New York

Kripke S (2013) Reference and existence: the John Locke lectures. Oxford University Press, New York

Langsam H (1997) The theory of appearing defended. Philos Stud $87: 33-59$

Larson R, Segal G (1995) Knowledge of meaning. MIT Press, Cambridge
Lepore E, Ludwig K (2000) The semantics and pragmatics of demonstratives'. Mind 109:199-240

Lewis D (1981) What puzzling pierre does not believe. Australas J Philos 59. Reprinted in David Lewis, Papers in Metaphysics and Epistemology. Cambridge University Press, Cambridge, 1999

Lewis D (1986) On the plurality of worlds. Blackwell, Oxford

Martin MGF (1997) The reality of appearances. In: Sainsbury M (ed) Thought and ontology. Franco Angelli, Milan

Martin MGF (2002) The transparency of experience. Mind Lang $17: 376-425$

McCulloch G (1989) The game of the name. Clarendon Press, Oxford

McDowell J (1977) On the Sense and reference of a proper name. Mind 86

McDowell J (1982) Truth-value gaps. In: Cohen LJ (ed) Logic, methodology, and philosophy of science VI. North Holland, Amsterdamn

McDowell J (1984) De re senses. Philos Q 34:283-294

McDowell J (1986) Singular thought and the extent of inner space. In: Pettit P, McDowell J (eds) Subject, thought and context. Oxford University Press, Oxford

McDowell J (1990) Peacocke and Evans on demonstrative content. Mind 99:255-266

McDowell J (1991) Intentionality de re. In: Lepore E, Van Gulick R (eds) John Searle and his critics. Basil Blackwell, Oxford

McDowell J (1994) Mind and world. Harvard University Press, Harvard

McDowell J (2005) Evans's Frege. In: Bermudez JL (ed) Thought, reference, and experience. Themes from the philosophy of Gareth Evans. Clarendon Press, Oxford

McGinn C (1982) The character of mind. Oxford University Press, Oxford

Millar A (1996) The idea of experience. Proc Aristot Soc 96:75-90

Noonan H (1986) Russellian thoughts and methodological solipsism. In: Butterfield J (ed) Language, mind, and logic. Cambridge University Press, Cambridge

Noonan H (1991) Object-dependent thoughts and psychological redundancy. Analysis 51:1-9

Peacocke C (1981) Demonstrative thought and psychological explanation. Synthese 49:187-217

Peacocke C (1983) Sense and content. Clarendon Press, Oxford

Peacocke C (1986) Analogue content. Proc Aristot Soc Suppl Vol 60:1-17

Peacocke C (1989) Perceptual content. Almog J, Perry J, Wettstein H (eds) Themes from Kaplan. Oxford University Press, Oxford

Peacocke C (1991) Demonstrative content: a reply to John McDowell. Mind 100:123-133

Peacocke C (1992) A study of concepts. MIT Press, Cambridge

Peacocke C (1993) Externalist explanation. Proc Aristot Soc 93:203-230

Pettit P, McDowell J (eds) (1986) Subject, thought and context. Oxford:Clarendon Press

Putnam H (1994) Sense, nonsense, and the senses: an inquiry into the powers of the human mind (the Dewey lectures). J Philos 91:445-517

Recanati F (1993) Direct reference. Blackwell, Oxford

Sainsbury M (2005) Reference without referents. Clarendon Press, Oxford

Salmon N (1986) Frege's puzzle. MIT Press, Cambridge

Schiffer S (1978) The basis of reference. Erkenntnis 13:171-206

Schiffer S (1987) Remnants of meaning. MIT Press, Cambridge

Searle J (1983) Intentionality. Cambridge University Press, Cambridge

Segal G (1989) The return of the individual. Mind 98:39-57

Snowdon P (1980-81). Perception, vision, and causation. Proc Aristot Soc 81:175-192

Snowdon P (1990) The objects of perceptual experience. Proc Aristot Soc Suppl Vol 64:121-150

Travis C (2004) The silence of the senses. Mind 113:59-94

Travis C (2011) Desperately seeking $\Psi$. Philos Issues 31:505-557 